\title{
Child abuse and neglect in sub-Saharan Africa
}

\author{
O. O. Famuyiwa
}

Child abuse could be defined from predominantly legal, clinical and research perspectives, and attempts at an integrative enunciation are fraught with over-inclusiveness. Meadow (1989) proposed that a child is considered to be abused if he or she is treated by an adult in a way that is unacceptable in a given culture at a given time. This definition usefully incorporates the essential issues including secularity and diversity of socio-cultural norms which often create controversy in case detection and are particularly relevant to the debate.

Concern for victims of child abuse in Africa was expressed by the African Network of the International Society for the Prevention of Child Abuse and Neglect (ISPCAN, 1986) which gave five main presentations of child abuse: child labour, street wandering, sexual abuse, child battering and abandonment. Such a broad spectrum seems rational in that in health planning for the international community, with its variable, legal, cultural and clinical views of abuse, it ensures that the minimal number of genuine abuses would be undetected, although there is the inherent danger of inclusion of innocent cases.

\section{Child labour}

According to the International Labour Organisation (ILO), about 10 million children under 15 years in Africa are in formal employment, working long hours with poor pay and are exposed to substantial health hazards. Clinical reports (Onyango \& Male, 1982; Okehialam, 1984; Peltzer, 1986) corroborate the use of African children as agents of cheap labour, and highlight the deleterious impact of child labour on the child's physical and emotional well-being. Child labour involves lack of freedom of movement, long hours of work, lack of emotional warmth, underpayment and the expectation of the child to play adult labour roles. Evidence of the adverse cognitive effect of child labour is provided in a controlled study (Izuora \& Ebigbo, 1985) in which 50 randomly selected househelps with a mean age of 12.2 years (s.d. 3.1) were rated on Draw-a-Person test (using Ziller scoring scheme) and compared with age and gender-matched urban children who did not work. The average quotients of the subject and control groups were 86.18 (s.d. 23.25) and 106.80 (s.d. 19.34), respectively $(P<0.001)$.

It should be borne in mind that the link between economic hardship and abuse is complex. For example, poverty could encourage the employment of children for cheap but nonhazardous labour. On the other hand, cases of child labour could mask child abuse. Some of the ILO guidelines, i.e. minimum age for employment, 'light work', reasonable duration of work per day, and other criteria designed to minimise hazards to the child's health and education, should be useful in differentiating permissible labour from abuse. However, some of these criteria are perceived differently across national boundaries and even within the same country.

\section{Wandering}

This term refers to children, usually unkempt and with delinquent propensities, living rough in town (Khamala, 1985). The reasons for children taking to the street remain poorly understood (Diaz, 1986) particularly in relation to factors in the child rather than parental hostility and economic adversity (Famuyiwa, 1990). Delinquency and unrecognised developmental deviancies could be the antecedents to, rather than effects of, wandering, independent of parental negative behaviour. UNICEF identifies poverty. broken homes, parental aggression, and alcohol abuse as putative aetiological factors. It should be borne in mind that the link between economic hardship and child abuse is complex.

\section{Sexual abuse}

The western concept of sexual abuse as involvement of immature children in sexual activities that they do not fully comprehend, to which they are unable to give informed consent, or that violate the social taboos or family roles is largely valid for indigenous Africa, except cultural variability of acceptable behaviours creates some confusion in case identification. For example, 
arranged under-age marriages are common in some parts of the continent and doubt was often expressed as to whether a young girl fully gave consent to being betrothed.

Prevalence rates in Africa are very difficult to ascertain because of the fear of disclosure by victims and lack of proper documentation. Most of the girls by reasons of shame, fear or surprisingly respect for their usually older perpetrators, reported their experience to no one.

The rise in tourism along the North coast of the continent brought in its wake sporadic incidences of homosexual enticement and several forms of sexual exploitation of young girls by some Europeans (Ebigbo \& Abaga, 1990). Disturbing incidents of slavery and child prostitution have been reported and seemed fuelled by the indifference or greed of parents (Jinadu, 1986). However, these reports are based mainly on selective data obtained from law enforcement authorities. Underestimation was therefore very common.

\section{Physical battering}

Physical abuse of children is widely claimed to be rare in the third world; however, there are anecdotes from East Africa (Bwibo, 1972) and Nigeria (Ofodile, 1981). The author examined 328 radiologists' reports on X-ray films of total skeletal frame or localised body areas of all first attenders aged 0-12 years at this hospital during the four-year period 1 January 1987 to 31 December 1990. Sixty-nine of these reports reveal evidence of multiple bone fractures with or without evidence of rib or skull fracture. But corresponding case note records show that all but one (rickets) were apparently due to road traffic accidents involving several other people. And studying the case notes of children presenting with bruises, cuts, burns and other visible traumas ( $n=806$ ) during the same period, none was diagnosed (not even differentially) as battered child syndrome.

For a claim of low incidence to be upheld it is important to exclude low index of suspicion by doctors contingent to the presumptive rarity and what Speight (1989) called "emotional blocks in the minds of professionals". Secondly, diagnosis might be hampered by the blurred boundary between discipline and abuse and existing education policy is silent or vague on legitimacy of corporal punishment. Thirdly, some traditional 'therapeutic' measures such as burning a child's feet to control convulsion (Ofodile, 1981), and skin scarifications for relief of deep-seated pain such as cia gao (coin marks) in Vietnam and Cambodia, would according to UNICEF be tantamount to abuse. A test of reincarnation in some rural Nigerian communities is to amputate the top of a dying child's little finger and expect a stump at the next delivery. Malnutritional complexes such as kwashiorkor or marasmus could be due to deliberate neglect rather than honest ignorance or poverty. Furthermore, the inability of many families to afford the cost of treatment and inadequate public amenities, e.g. transportation, could exclude genuine (mostly nonsevere) cases of physical abuse from medical attention.

However, there could be some credence to the observed low incidence, in that living congestion in the third world is not conducive to child maltreatment and furthermore adults in such a close-knit system have several persons onto whom their sadistic impulses could be directed. A midway model is the conception of abuse in terms of a yet-to-be identified syndrome equivalent to larval depression.

\section{Abandonment}

Valid and adequate information on abandonment are difficult to obtain due mainly to failure of offending parents to show up out of guilt, shame, judicial repercussions or a combination of these. However, some Euro-American missionaries identified inter alia breech birth, multiple births, perinatal maternal mortality, congenital malformations and protracted illness of the baby as reasons for abandonment. These reasons seemed to have given way in recent decades to economic impoverishment due to famine, war or defective political governance.

The author examined records of all public complaints lodged with the two Juvenile Police units serving metropolitan Lagos (population 5 million). Taking care to exclude duplication by checks on registers of the three Motherless Babies Homes (a repository of Police disposals) in the city, abandonment accounted for $4.1 \%$ (113 cases) of all complaints. There was no significant monthly variation or sex difference and sites of abandonment were classified as high risk (HR) or low risk (LR) based on perceived chances of the victim being rescued. HR sites $(16.8 \%)$ included refuse dumping grounds, under bridges, bushes and railway lines. LR sites $(83.2 \%)$ were mainly bus-stops, hospital premises, market places, a familiar person's house, private compounds, stranger's house, police posts and public toilets. These data, with reservations, indicate that in a large majority of abandonment cases in Nigeria, the intent was not to put the child's life in serious danger. 


\section{Conclusion}

There is a large hiatus in our knowledge of child abuse in the third world. Prospective studies are required to ascertain accurate epidemiological data. Empirical evidence strongly indicates economic hardship faced by perpetrators of child labour, abandonment and sexual abuse. In support of this corollary, indicators of socioeconomic viability such as the gross national product per capita and the under-5 mortality rate are deplorably low in sub-Saharan Africa and South Asia. Priority attention needs to be given to the imbalance between population growth and resources. A remedial integrative approach as proposed by UNICEF (1995) is to modify the Population-Poverty-Environment (PPE) spiral in favour of social welfarism in the hope of achieving an acceptable level of child care.

\section{References}

BwiBo. N. O. (1972) Battered Baby Syndrome. East African Medical Journal, 49, 934.

DIAZ, R. (1986) The major routes towards the abandonment and abuse of children in Africa. In Child Labour in Africa (eds P. Ebigbo, et al). Enugu, Nigeria: ANPPCAN Publications, Chuka Printing Company.

Ebigbo, P. \& AbaGA, S. (1990) Sexual Abuse of Street Trading Girls in Enugu. 8th ISPCAN International Congress on Child Abuse and Neglect. Hamburg. September 2-6.
FAMUYTwA. O. O. (1990) Current Trends of Child Abuse and Neglect in West Africa. Proceedings of the 15th Annual General and Scientific Meeting, West African College of Physiclans, Accra, Ghana.

IZUORA, G. I. \& EBIGBO, P. O. (1985) Assessment of househelps in Enugu using the Draw-a-Person Test. Nigerian Medical Practitioner, 8, 21-23.

JiNADU, M. L. (1986) Cotonou children: an obnoxdous aspect of child labour in Nigeria. In Children in Difficult Curcumstances (eds N. Bwibo \& P. Onyango), pp. 4752. Works Ltd, Nairobi. ANPPCAN Publications, City Printing.

KHAMALA, R. (1985) Street wandering children. In Children in Especially Disadvantaged Circumstances (eds $\mathrm{N}$. Bwibo \& P. Onyango). Nairobi: ANPPCAN Publications, City Printing Works Ltd.

MEADOw, R. (1989) ABC of child abuse epidemiology. British Medical Journal, 298, 727-730.

OfodiLE, F. A. (1981) Child abuse and neglect in Africa. Postgraduate Doctor, 3, 94-98.

OKeHIALAM, T. C. (1984) Child abuse in Nigeria. International Journal of Child Abuse and Neglect. 8, 1.

ONYANGO, P. \& MALE. D. (1982) Psychological effects of child labour. In Child Labour \& Health. Proceedings of the First National Workshop on Child Labour \& Health. Journals of Eastern Africa Development. University of Nairobi, Kenya.

PELTZER, K. (1986) Children as commercial farm labourers and prostitutes in Africa. In Child Labour in Africa leds P. Ebigbo, et al. pp. 34-38. Enugu, Nigeria: ANPPCAN Publications, Chuka Printing Company.

SPEIGHT, N. (1989) Non accidental injury. British Medical Journal, 298, 879-881.

UNICEF (1995) The State of the World's Children.

O. O. Famuyiwa, Department of Psychiatry, College of Medicine, University of Lagos, Harvey Road, YABA PMB 12003, Lagos, Nigeria 